\title{
Correction to: Perceived economic self-sufficiency: a country- and generation-comparative approach
}

Jale Tosun $^{1} \cdot$ José L. Arco-Tirado $^{2} \cdot$ Maurizio Caserta $^{3} \cdot$ Zeynep Cemalcilar $^{4}$. Markus Freitag $^{5} \cdot$ Felix Hörisch ${ }^{1}$ - Carsten Jensen ${ }^{6} \cdot$ Bernhard Kittel $^{7}$. Levente Littvay $^{8}$ - Martin Lukeš ${ }^{9}$ William A. Maloney ${ }^{10}$ - Monika Mühlböck ${ }^{7}$. Emily Rainsford $^{10}$ - Carolin Rapp ${ }^{11}$ - Bettina Schuck ${ }^{12} \cdot$ Jennifer Shore $^{13}$. Nadia Steiber $^{14} \cdot$ Nebi Sümer $^{15} \cdot$ Panos Tsakloglou $^{16} \cdot$ Mihaela Vancea $^{17}$. Federico Vegetti ${ }^{18}$

The original article can be found online at https://doi.org/10.1057/s41304-018-0186-3.

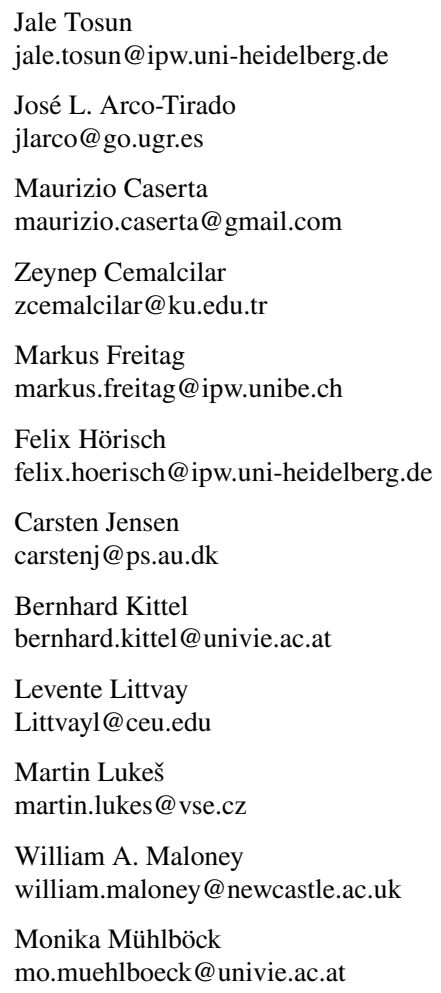


Emily Rainsford

Emily.Rainsford@newcastle.ac.uk

Carolin Rapp

mail@ carolinrapp.com

Bettina Schuck

bettina.schuck@ipw.uni-heidelberg.de

Jennifer Shore

Jennifer.shore@mzes.uni-mannheim.de

Nadia Steiber

steiber@ihs.ac.at

Nebi Sümer

nsumer@metu.edu.tr

Panos Tsakloglou

tsaklog@aueb.gr

Mihaela Vancea

mihaela.vancea@upf.edu

Federico Vegetti

vegetti.fede@gmail.com

1 Institute of Political Science, Heidelberg University, Bergheimer Strasse 58, 69115 Heidelberg, Germany

2 University of Granads, Avda. del Hospicio, 18071 Granada, Spain

3 University of Catania, Piazza Università, 2, 95124 Catania, CT, Italy

4 Koc University, 34450 Sariyer, Istanbul, Turkey

5 Institute of Political Science, University of Bern, Fabrikstrasse 8, 3012 Bern, Switzerland

6 Aarhus University, Bartholins Allé 7, 8000 Aarhus C, Denmark

7 University of Vienna, Oskar-Morgenstern-Platz 1, 1090 Vienna, Austria

8 Central European University, Nador u. 9, Budapest 1051, Hungary

9 Department of Entrepreneurship, University of Economics, Prague, W. Churchill Sq. 4, 13067 Prague 3, Czech Republic

10 Newcastle University, Newcastle upon Tyne NE1 7RU, UK

11 University of Copenhagen, Øster Farimagsgade 5, 1353 Copenhagen, Denmark

12 Institute of Political Science, Heidelberg University, Bergheimerstr. 20, Heidelberg, Germany

13 Mannheim Centre for European Social Research, University of Mannheim, MZES, 68131 Mannheim, Germany

14 Institute for Advanced Studies, Josefstädter Str. 39, 1080 Vienna, Austria

15 Middle East Technical University, B236 Social Sciences Building, 06800 Ankara, Turkey

16 International and European Economic Studies, Athens University of Economics and Business, 76 Patission Str., 10434 Athens, Greece

17 Pompeu Fabra University, Plaça de la Mercè, 10, 08002 Barcelona, Spain

18 Department of Social and Political Sciences, University of Milan, Via Conservatorio 7, 20122 Milan, Italy 


\section{Correction to: Eur Polit Sci}

\section{https://doi.org/10.1057/s41304-018-0186-3}

After online first publication of the article, it was noticed that the family name of author Panos Tsakloglou was erroneously misspelt as Tsakoglou. The original article has been corrected.

Open Access This article is distributed under the terms of the Creative Commons Attribution 4.0 International License (http://creativecommons.org/licenses/by/4.0/), which permits unrestricted use, distribution, and reproduction in any medium, provided you give appropriate credit to the original author(s) and the source, provide a link to the Creative Commons license, and indicate if changes were made. 